Revista Brasil. Bot., V.25, n.2, p.147-160, jun. 2002

\title{
Táxons de Mucor Fresen. (Zygomycota) em fezes de herbívoros, Recife, PE, Brasil
}

\author{
MARIA H. ALVES ${ }^{1,2,4}$, SANDRA F.B. TRUFEM ${ }^{3}$ e ADAUTO I. MILANEZ ${ }^{3}$
}

(recebido: 04 de outubro de 2000; aceito: 21 de fevereiro de 2002)

\begin{abstract}
Taxa of Mucor Fresen. (Zygomycota) from herbivorous dung, Recife, Pernambuco State, Brazil). To contribute to the knowledge of Mucorales (Zygomycota) in the northeastern of Brazil (Recife - Pernambuco State), a total of 120 samples of herbivorous dung have been collected monthly from June 1997 to May 1998. The dung was produced by the following animals: Bison bonasus H. Smith, Bos indicus L., Bubalus bubalis H. Smith, Capra hircus L., Oryctolagus cuniculus Lilljeborg, Dasyprocta fuliginosa Wagler, Taurotragus oryx Wagner, Equus caballus L., Ovis aries L. and Mazama gouazoubira Fischer, which were mantained captive in the "Parque Dois Irmãos" and in the "Departamento de Zootecnia da Universidade Federal Rural de Pernambuco". The samples were mantained in wet chambers at room temperature and observed during 15 days. The isolates were inoculated into Petri dishes containing Potato Dextrose Agar (PDA) and/or Synthetic Mucor Agar (SMA). Twelve taxa were identified, 11 already known and a new form, as follows: Mucor circinelloides f. circinelloides, M. circinelloides f. griseo-cyanus, M. circinelloides f. janssenii, M. circinelloides f. lusitanicus, M. hiemalis f. hiemalis, M. hiemalis f. luteus, M. genevensis, M. piriformis f. piriformis, M. piriformis f. nanus, M. racemosus f. chibinensis, M. subtilissimus and M. variosporus. Except for the Bubalus bubalis dung, all presented taxa of Mucor, with higher diversity in those of Bison bonasus, Oryctolagus cuniculus, Dasyprocta fuliginosa and Mazama gouazoubira. The highest index of similarity (75\%) on taxa of Mucorales occurred between Dasyprocta fuliginosa and Ovis aries, as well as, between Capra hircus and Oryctolagus cuniculus dung. Descriptions, comments, illustrations and keys for the identified taxa have been included.
\end{abstract}

RESUMO - (Táxons de Mucor Fresen. (Zygomycota) em fezes de herbívoros, Recife, PE, Brasil). Visando contribuir para o conhecimento sobre Mucorales (Zygomycota) em Recife, PE, foram realizadas coletas mensais, de junho/1997 a maio/1998, totalizando 120 amostras de fezes dos herbívoros: Bison bonasus H. Smith, Bos indicus L., Bubalus bubalis H. Smith, Capra hircus L., Oryctolagus cuniculus Lilljeborg, Dasyprocta fuliginosa Wagler, Taurotragus oryx Wagner, Equus caballus L., Ovis aries L. e Mazama gouazoubira Fischer, mantidos em cativeiro no Parque Dois Irmãos e no Departamento de Zootecnia da Universidade Federal Rural de Pernambuco. As amostras de fezes foram acondicionadas em câmara úmida (placa de Petri) à temperatura ambiente sendo observadas diariamente, do $2^{\circ}$ ao $15^{\circ}$ dia de incubação. As colônias de interesse foram isoladas e, após desenvolvimento, mantidas em Batata Dextrose Ágar (BDA) e/ou "Synthetic Mucor Agar" (SMA). Foram identificados 11 táxons já conhecidos e uma forma nova: Mucor circinelloides f. circinelloides, M. circinelloides f. griseo-cyanus, M. circinelloides f. janssenii, M. circinelloides f. lusitanicus, M. hiemalis f. hiemalis, M. hiemalis f. luteus, M. genevensis, $M$. piriformis f. piriformis, M. piriformis f. nanus, M. racemosus f. chibinensis, M. subtilissimus e M. variosporus. Com exceção das fezes de Bubalus bubalis, todas desenvolveram representantes de táxons de Mucor, apresentando maior diversidade as fezes de Bison bonasus, Oryctolagus cuniculus, Dasyprocta fuliginosa e Mazama gouazoubira. O maior índice de similaridade (75\%) foi verificado em táxons de Mucorales nas fezes de Dasyprocta fuliginosa e Ovis aries, assim como de Capra hircus e Oryctolagus cuniculus. Chave para identificação dos táxons isolados, assim como descrições, comentários e ilustrações foram incluídos.

Key words - Mucorales, Mucor spp., taxonomy, herbivorous dung, Recife

\section{Introdução}

O gênero Mucor Micheli compreende cerca de 80 espécies cosmopolitas, sendo considerado o mais representativo e estudado dentre os gêneros de

\footnotetext{
1. Parte da tese de doutorado do primeiro autor.

2. Universidade Estadual Vale do Acaraú, Coordenação de Biologia, Av. da Universidade, 850, 62040-370 Sobral, CE, Brasil.

3. Instituto de Botânica, Caixa Postal 4005, 01061-970 São Paulo, SP, Brasil.

4. Autor para correspondência: helena_alves@hotmail.com.br
}

Mucoraceae (Domsch et al. 1995). Os representantes de Mucor reproduzem-se, assexuadamente, por meio de aplanosporos formados internamente em esporângios e clamidosporos; sexuadamente, pela fusão de dois gametângios geneticamente compatíveis, pertencentes ou não ao mesmo micélio e dando origem ao zigosporo. A maioria das espécies de Mucor vive como sapróbia no solo, grãos, flores, frutos, restos de vegetais, agáricos carnosos, fezes de herbívoros (Hesseltine \& Ellis 1973, Trufem 1981a, Alexopoulos et al. 1996, Viriato 1996) e solo afetado por fezes de aves (Schoenlein-Crusius 
et al. 1996). Em fezes de herbívoros, há trabalhos que demonstram, inclusive a sucessão fúngica (Trufem 1978, Trufem \& Viriato 1985, Foos et al. 2001, Richardson 2001).

Os mucoráceos desempenham papel importante nos processos iniciais de reciclagem, sendo responsáveis pela colonização primária do substrato utilizando-se dos açúcares de estrutura molecular mais simples (glicose), daí serem conhecidos como "fungos do açúcar" (Hesseltine \& Ellis 1973). Apesar disso, poucos pesquisadores demonstraram interesse por fungos que utilizam fezes como substrato. Nesse contexto, Trufem (1978, 1981a, 1984), Trufem \& Viriato (1985), Viriato (1996) pesquisaram táxons de Mucorales em fezes de animais herbívoros da Fundação Parque Zoológico do Estado de São Paulo, mencionando entre os táxons de mucoráceos encontrados treze, dez, três, seis e nove, respectivamente, pertencentes a Mucor. Schoenlein-Crusius et al. (1996) trabalhando com solo afetado por fezes de aves, no Parque Estadual das Fontes do Ipiranga, também no estado de São Paulo, relataram 19 táxons de Mucorales entre os quais 10 de Mucor.

Por outro lado, o gênero Mucor ganha destaque na biotecnologia sendo responsável pela produção de várias enzimas como: amilase, lipase, pectinase e protease (Domsch et al. 1995, Petruccioli \& Federici 1992). Mucor hiemalis, M. racemosus (Perraud \& Laboret 1995) e M. miehei (Escobar \& Barnett 1993) são espécies que apresentam atividade enzimática proteásica de importância comercial.

Schipper (1973, 1975, 1976, 1989) e Schipper \& Samson (1994) realizaram estudos relevantes sobre a variabilidade e a morfologia de Mucor hiemalis, M. mucedo, M. circinelloides, M. racemosus, M. laxorrhizus, M. nanus, $M$. grandis e espécies relacionadas, posicionando-os taxonomicamente e elaborando chaves para identificação.

Ao contrário do que ocorre no exterior, no Brasil são poucos os trabalhos ligados à diversidade de Mucorales em nível específico, existindo apenas referências para o estado de São Paulo (Trufem 1978, 1981a, b, c, 1984, Trufem \& Viriato 1985, Viriato \& Trufem 1985a, b, Schoenlein-Crusius et al. 1996, Viriato 1996) e outras para a região Nordeste (Batista et al. 1961a, b, c, d, 1964, 1967a, b, Upadhyay 1967, 1969, 1970, 1973, Lira 1971, Santos 2000, Cavalcante 2000).

Tendo em vista a carência de levantamentos realizados com o gênero Mucor no Brasil, principalmente na região Nordeste, e a necessidade de se descobrir novos organismos com fins biotecnológicos, foi elaborado o presente trabalho utilizando fezes de herbívoros do Departamento de Zootecnia da Universidade Federal Rural de Pernambuco e do Parque Dois Irmãos, ambos situados na cidade de Recife, PE. Acrescente-se que as fezes de herbívoros constituem excelentes substratos pois oferecem os nutrientes requeridos para o desenvolvimento de representantes de mucoráceos.

\section{Material e métodos}

Mensalmente, de junho/1997 a maio/1998, foram coletadas amostras de fezes de animais herbívoros: bisão (Bison bonasus H. Smith), boi (Bos indicus L.), búfalo (Bubalus bubalis H. Smith), cabra (Capra hircus L.), coelho (Oryctolagus cuniculus Lilljeborg), cotia (Dasyprocta fuliginosa Wagler), eland (Taurotragus oryx Wagner), cavalo (Equus caballus L.), ovelha (Ovis aries L.) e veado-catingueiro (Mazama gouazoubira Fischer), mantidos em cativeiro no Parque Dois Irmãos e/ou Departamento de Zootecnia da Universidade Federal Rural de Pernambuco.

As amostras de fezes foram coletadas com o auxílio de espátula e/ou pinça, previamente mergulhadas em álcool $70^{\circ}$ GL e acondicionadas em sacos plásticos. Em laboratório, as amostras foram distribuídas em placas de Petri (duplicatas) mantidas em câmara úmida e incubadas à temperatura ambiente $\left(28 \pm 2^{\circ} \mathrm{C}\right)$ e luminosidade ambiente.

A partir do segundo dia de incubação, os fungos de interesse foram isolados em placa de Petri contendo meio seletivo para Mucorales (Bärtschi et al. 1991). Para manutenção, conservação e estudo dos isolados obtidos, estes foram repicados em Synthetic Mucor Agar-SMA (Hesseltine \& Anderson 1957) e/ou em Batata Dextrose Ágar (BDA).

As identificações foram realizadas com base em observações macro e microscópicas apoiadas nos trabalhos de Schipper (1973, 1975, 1976, 1989), Schipper \& Samson (1994), Domsch et al. (1995), O’Donnell (1979), Trufem (1978, 1981a, 1984), Trufem \& Viriato (1985) e Viriato (1996).

Para verificar a similaridade entre as micotas dos diferentes substratos foi aplicado o índice de similaridade de Sörensen IS $=2 \mathrm{C} /(\mathrm{A}+\mathrm{B}) \times 100$, onde $\mathrm{A}=$ número de táxons ocorrentes no substrato $\mathrm{A}, \mathrm{B}=$ número de táxons ocorrentes no substrato $\mathrm{B}$ e $\mathrm{C}=$ número de táxons comuns a ambos os substratos.

Os isolados foram depositados nas seguintes coleções de culturas: SPC - Seção de Micologia e Liquenologia do Instituto de Botânica da Secretaria do Meio Ambiente do Estado de São Paulo e URM - Universidade de Recife do Departamento de Micologia da Universidade Federal de Pernambuco. 


\section{Resultados e Discussão}

Foram identificados 11 táxons já conhecidos para a ciência e propõe-se uma nova forma como se segue: M. circinelloides van Tieghem f. circinelloides Schipper, M. circinelloides van Tieghem $\mathrm{f}$. griseo-cyanus (Hagem) Schipper, M. circinelloides van Tieghem f. jansseni (Lendner) Schipper, M. circinelloides van Tieghem f. lusitanicus
(Bruderlein) Schipper, M. genevensis Lendner, M. hiemalis Wehmer f. hiemalis Schipper, M. hiemalis Wehmer f. luteus (Linnemann) Schipper, M. piriformis Fischer f. piriformis, M. piriformis Fischer f. nanus Alves \& Trufem (nova forma), M. racemosus Fres. f. chibinensis (Neophytova) Schipper, M. variosporus Schipper e M. subtilissimus Oudem.

Os táxons mencionados podem ser identificados com base na chave proposta a seguir:

Chave de identificação dos táxons estudados

1. Formação de zigosporos a partir de culturas monospóricas Mucor genevensis

1'. Zigosporos não formados em culturas monospóricas 2

2. Colônias com micélio delicado, aspecto sedoso, prostrando-se imediatamente após a abertura da placa de Petri M. subtilissimus

2'. Colônias com micélio vigoroso, cotonoso, mantendo-se ereto com a abertura da placa de Petri ..... 3

3. Esporangiosporos irregulares quanto à forma (globosos, ovóides, cilíndricos, fusiformes, contorno irregular)......

3'. Esporangiosporos regulares quanto à forma (elipsoidais) . 4

4. Parede esporangial persistente 6

4'. Parede esporangial difluente M. variosporus

5. Columelas obovóides; esporos elipsoidais, plano convexos, fusiformes, 2,5-10 × 2-7,5 $\mu \mathrm{m}$ .. 5

5'. Columelas globosas; esporos longo-elípticos, 2,5-8,1(12,5) $\times 1-5 \mu \mathrm{m}$

M. hiemalis f. hiemalis

6. Esporângios com mais de $100 \mu \mathrm{m}$ diâm, freqüentemente chegando aos 150 (250) $\mu \mathrm{m}$ diâm., columelas obovóides, piriformes, panduriformes 7

6'. Esporângios até 80(90) $\mu \mathrm{m}$ diâm, columelas globosas ou menos freqüentemente obovóides 8

7. Colônias com mais de $2,5(5,0) \mathrm{cm}$ alt.

7'. Colônias até $0,3 \mathrm{~cm}$ alt. M. piriformis f. piriformis

8. Ocorrência de clamidosporos no micélio aéreo M. piriformis f. nanus

8'. Ausência de clamidosporos no micélio aéreo. M. racemosus f. chibinensis

9. Colônias esbranquiçadas, passando a tons de cinza com a idade . 9

9'. Colônias amareladas, passando a tons de castanho com a idade. 10

10. Columelas com tons de cinza-azulado, esporangiosporos elipsoidais 5-11,2 × 2,5-6,2 $\mu \mathrm{m}$ M. circinelloides f. griseo-cyanus

10'. Columelas com tons de cinza, esporangiosporos globosos a levemente subglobosos, 3-10 $\times$ 2,5-7,0 $\mu \mathrm{m}$

M. circinelloides f. janssenii

11. Columelas obovóides, esporangiosporos elipsoidais 5-8,7 $\times 3,7-5,5 \mu \mathrm{m} \ldots$ M. circinelloides $\mathrm{f}$. circinelloides 11'. Columelas globosas, esporangiosporos elipsoidais $2,5-5 \times 2-3,1 \mu \mathrm{m}$. M. circinelloides f. lusitanicus

Mucor circinelloides van Tieghem f. circinelloides, Annls. Sci. nat. I: 94. 1875.

Figuras 1-5.

Colônia, com seis dias em BDA, 0,5-1,2 cm alt. $\times$ 8,2-9 cm diâm., verso cinza-amarelado a castanho, reverso amarelado, amarelo mais intenso no local do inóculo, esporangióforos em duas camadas: a inferior com centro cotonoso e aspecto pulverulento em direção à periferia, a superior, cotonosa frouxa a cotonosa densa com a idade. Fototropismo positivo. Esporangióforos septados ou não (2,5-)5-12,5(-17,5) $\mu \mathrm{m}$ diâm., simpodialmente ramificados, com ramificações longas e curtas, estas últimas recurvadas, parede com incrustações, com ou sem conteúdo amarelado, esporângios 
globosos (32,5-)37,5-85(-87,5) $\mu \mathrm{m}$ a leve depressos, amarelos, castanhos quando jovens, passando a negros com a idade, aspecto metálico brilhante, parede difluente nos maiores e persistente nos menores, columelas maiores obovóides $21,2-57,5(-60) \times$ $(-17,5) 20-45 \mu \mathrm{m}$, columelas menores globosas (7,5-)10-32,5(-35) $\mu \mathrm{m}$, cinza-acastanhada, colarete presente, esporangiosporos elipsoidais 5-8,7 $\times$ $3,7-5,5(-6,2) \mu \mathrm{m}$ ou globosos a subglobosos 3,7-6,2(-7,5) $\mu \mathrm{m}$, hialinos, parede lisa, zigosporos não observados.

Isolado de fezes de boi (julho/1997) e bisão (janeiro/maio/1998). col. M.H. Alves. Linhagens registradas: SPC 1.768 e URM 4.136.

As características observadas neste táxon apresentam boa correspondência com os descritos por Schipper (1976) que cita colônia mais baixa (6 mm), esporângio com até $80 \mu \mathrm{m}$, columela $54 \times 49 \mu \mathrm{m}$ e esporangiosporos menores, 4,4-6,8 $\times 3,7-4,7 \mu \mathrm{m}$. Neste táxon, pode ocorrer variabilidade na altura $(2-20 \mathrm{~mm})$, coloração, forma e dimensões das microestruturas sendo as diferenças entre as variedades ou formas muito pequenas. Assim, este isolado difere das demais variedades ou formas de $M$. circinelloides por apresentar columela cinza-acastanhada. O táxon foi referido, para o Estado de São Paulo, por Trufem (1978) isolado do solo e do folhedo e por Schoenlein-Crusius et al. (1996) isolado de solo afetado por fezes de aves. Para o Estado de Pernambuco, foi isolado de amostras de água e de solo por Santos (2000).

Mucor circinelloides van Tieghem f. griseo-cyanus (Hagem) Schipper, Studies in Mycology 12:12. 1976. Figuras 6-10.

Colônia, com seis dias em SMA, 0,5-1,2 cm alt. $\times$ $9 \mathrm{~cm}$ diâm., verso cinza-amarelado a cinza-escuro, reverso amarelado, amarelo mais intenso no local do inóculo, esporangióforos em duas camadas: a inferior com centro cotonoso e aspecto pulverulento em direção à periferia, a superior cotonosa frouxa à cotonosa densa com a idade. Fototropismo positivo. Esporangióforos (5-)7,5-15(-17,5) um diâm., ramificado simpodialmente, com ramificações longas e curtas, estas últimas recurvadas, parede com incrustações, septado ou não, esporângios globosos a levemente depresso (15-)20-72,5(-75) $\mu \mathrm{m}$, amarelo quando jovem passando de cinza-escuro a negro com a idade, aspecto brilhante, parede difluente deixando pequeno colarete nas columelas maiores e persistente nas menores, columelas maiores obovóides $(27,5-) 30-65(-82,5) \times(20-)$
25-62,5(-77,5) $\mu \mathrm{m}$, columelas menores globosas $10-50(-52,5) \mu \mathrm{m}$, cinza com nuances de cinza-azulado, esporangiosporos elipsoidais a plano-convexos 5-11,2 $\times 2,5-6,2 \mu \mathrm{m}$ ou globosos a subglobosos 3,7-6,2 $\mu \mathrm{m}$, hialinos, paredes lisa, zigosporos não observados.

Isolado de fezes de bisão (junho/1997, abril/1998), veado-catingueiro (outubro/1997, fevereiro/1998), carneiro (março/maio/1998), cabra, coelho e eland (maio/1998), col. M.H. Alves. Linhagens registradas: SPC 1.769 e URM 4.183.

Esta linhagem possui características semelhantes àquelas descritas por Schipper (1976) que relata esporangióforos com até 6(10) $\mu \mathrm{m}$, esporângios até $60 \mu \mathrm{m}$, columelas $38 \times 35 \mu \mathrm{m}$ e esporangiosporos 4,4-6,1 × 3,8-4,4 $\mu \mathrm{m}$. Entretanto, em sua discussão, a autora afirma que talvez o isolado por ela estudado tenha perdido as características originais. Esta linhagem difere das demais variedades ou formas de $M$. circinelloides por apresentar columela cinza-azulada. Este táxon foi referido, para o Estado de São Paulo, por Trufem (1978) isolado de amostras de solo e de folhedo e por Schoenlein-Crusius et al. (1996) isolado de amostras de solo afetado por fezes de aves. Santos (2000) isolou representante deste táxon de amostras de água e de solo coletadas no Estado de Pernambuco.

Mucor circinelloides van Tieghem f. janssenii (Lendner) Schipper, Studies in Mycology 12:13. 1976. Figuras 11-16.

Colônia, com cinco dias em SMA, $0,5-1,5 \mathrm{~cm}$ alt. $\times 9$ cm diâm., verso cinza-claro a cinza-escuro, reverso cinzaamarelado, amarelo mais intenso no local do inóculo, esporangióforos em duas camadas: a inferior com centro cotonoso e aspecto pulverulento em direção à periferia, a superior, cotonosa frouxa quando jovem, à cotonosa densa, com a idade. Fototropismo positivo. Esporangióforos 7,5-17,5 $\mu \mathrm{m}$, ramificados simpodialmente, ramificações longas e curtas, tornando-se mais ramificado em direção ao ápice, com incrustações na parede, com ou sem conteúdo amarelo, esporângios globosos 20-90 $\mu \mathrm{m}$ a leve subglobososos, amarelos quando jovens passando a negros com a idade, aspecto brilhante, parede persistente, colarete desenvolvido, columelas maiores obovóides 27,5-62,5 × 25-50 $\mu \mathrm{m}$, columelas menores globosas 10-50(-60) $\mu \mathrm{m}$, esporangiosporos subglobosos 3-10(-11,2) $\times 2,5-7 \mu \mathrm{m}$ ou globosos 3-8 $\mu \mathrm{m}$, hialinos, parede lisa, zigosporos não observados.

Isolado de fezes de eland, veado-catingueiro (julho/1997), coelho (agosto/outubro/1997), col. M.H. Alves. Linhagens registradas: SPC 1.770 e URM 4.141. 
As características apresentadas por esta linhagem concordam com aquelas mencionadas na descrição fornecida por Schipper (1976) diferindo apenas em algumas medidas de microestruturas citadas pela autora, como colônia mais baixa até 3(6) mm, esporangióforos até $7(10) \mu \mathrm{m}$, esporângio até $60(80) \mu \mathrm{m}$, columela obovóide $35 \times 33 \mu \mathrm{m}$ e esporangiosporos (3-)3,5-5,5(-6) $\mu \mathrm{m}$. Entretanto as diferenças apresentadas por esta linhagem não são relevantes, pois a mesma foi isolada recentemente não se tratando de espécime estocada como as estudadas pela citada autora, e também, porque a linhagem possui características próprias, como parede esporangial persistente e esporangiosporos subglobosos, o que a separa das demais formas. O táxon foi citado, para o Estado de São Paulo, por Trufem (1978) isolado de amostras de solo e de folhedo, por Viriato (1996) isolado de fezes de zebra e por Schoenlein-Crusius et al. (1996) isolado de solo afetado por fezes de aves. Santos (2000) reportou a ocorrência deste táxon no Estado de Pernambuco isolado de amostras de água e de solo.

Mucor circinelloides van Tieghem f. lusitanicus (Bruderlein) Schipper, Studies in Mycology 12:9. 1976. Figuras 17-21.

Colônia, com seis dias em BDA, $1 \mathrm{~cm}$ alt. $\times 9 \mathrm{~cm}$ diâm., verso cinza-amarelado a castanho reverso amarelado, amarelo mais intenso no local do inóculo, esporangióforos em duas camadas: a inferior com centro cotonoso e aspecto pulverulento em direção à periferia, a superior, cotonosa frouxa quando jovem à cotonosa densa com a idade. Fototropismo positivo. Esporangióforos 6,2-16,2 $\mu \mathrm{m}$ diâm., ramificados simpodialmente, recurvados, parede com incrustações, com ou sem conteúdo amarelo, esporângios globosos 21,5-92,5 $\mu \mathrm{m}$, amarelos quando jovens passando a castanhos com a idade, aspecto brilhante, parede difluente, columelas globosas a subglobosas $15-55 \mu \mathrm{m}$, com colarete, esporangiosporos elipsoidais 2,5-5 $\times 2-3,1 \mu \mathrm{m}$, hialinos, paredes lisas, zigosporos não observados.

Isolado de fezes de veado-catingueiro (abril/1998), col. M.H. Alves. Linhagens registradas: SPC $1.771 \mathrm{e}$ na URM 4.137.

Esta linhagem possui características que concordam com a descrição fornecida por Schipper (1976), entretanto, a autora cita colônia até $3 \mathrm{~mm}$ alt., esporangióforos até $14 \mu \mathrm{m}$ diâm., esporângio até 60(75) $\mu \mathrm{m}$ diâm., columela até 35(45) $\mu \mathrm{m}$ diâm. e esporangiosporos 5,5-17,6 $\times 3,4-12,8 \mu \mathrm{m}$, sendo estes de forma bizarra. Afirma também que esporangiosporos elipsoidais $(2,5-) 5,4-6,8 \times(2,3-) 3-4,5 \mu \mathrm{m}$ de outros isolados, geralmente são uniformes no tamanho e forma, o que corresponde ao material estudado. A citada autora ressalta ainda, que a altura da colônia também pode variar de 2 a $15 \mathrm{~mm}$. O táxon difere de Mucor circinelloides f. circinelloides e $M$. circinelloides $\mathrm{f}$. griseo-cyanus pela dimensão dos esporangiosporos, que são menores nesta linhagem e difere de Mucor circinelloides f. janssenii pela forma e dimensão dos esporangiosporos. Este táxon foi referido, para o Estado de São Paulo, por Trufem (1978) que o isolou de amostras de solo e de folhedo. Santos (2000) isolou representante deste táxon de amostras de água e de solo coletadas no Estado de Pernambuco.

Mucor genevensis Lendner. Les Mucorinées de la Suisse. In Materiaux pour la Flore Cryptogamique Suisse. Vol.3, fasc. I. Berne.1908.

Figuras 22-26.

Colônia, com cinco dias em SMA, 1-2,2 cm alt. $\times$ $9 \mathrm{~cm}$ diâm. cotonosa densa, verso amarelo-claro reverso amarelo-queimado (abricot), com a idade. Fototropismo positivo. Esporangióforos em uma só camada, $(3,7) 5-12,5 \mu \mathrm{m}$, ramificados de forma monopodial, esporângios globosos a depressos 30-95 $\mu \mathrm{m}$, inicialmente brancos, amarelos a castanho-escuro, na maturidade, columelas globosas 17,5-45 $\mu \mathrm{m}$, esporangiosporos longo elípticos 2,5-10 $\times 1-5 \mu \mathrm{m}$, às vezes, plano-convexos, hialinos, com granulosidade refringente, zigosporos globosos a ligeiramente depressos 45-105 × 30-105 $\mu \mathrm{m}$, suspensores desiguais, com conteúdo de coloração amarelada quando jovens a laranja-avermelhados com a idade, verrucosos, castanhos a negros, translúcidos na periferia das verrugas, ornamentação enquadrando-se no grupo B de Schipper (1975).

Isolado de fezes de cotia (julho/setembro/1997), carneiro (novembro/1997), col. M.H. Alves. Linhagens registradas: SPC 1.772 e URM 4.188.

O táxon possui caracteres concordantes com o material descrito por Schipper (1973), que cita colônias mais baixas $(5 \mathrm{~mm})$, columelas piriforme-elipsoidais até $40 \times 32 \mu \mathrm{m}$, zigosporos até $80 \mu \mathrm{m}$, diferindo ligeiramente do material estudado que apresenta as medidas maiores. Entretanto, essas características não são significativas porque os demais caracteres são consistentes e as linhagens podem apresentar variabilidade. Este isolado difere de M. hiemalis $\mathrm{f}$. hiemalis e M. hiemalis f. luteus por apresentar colônia com reverso amarelo-queimado e formação de zigosporos a partir de cultura monospórica. Foi citado por Trufem (1981a) para o Estado de São Paulo como 

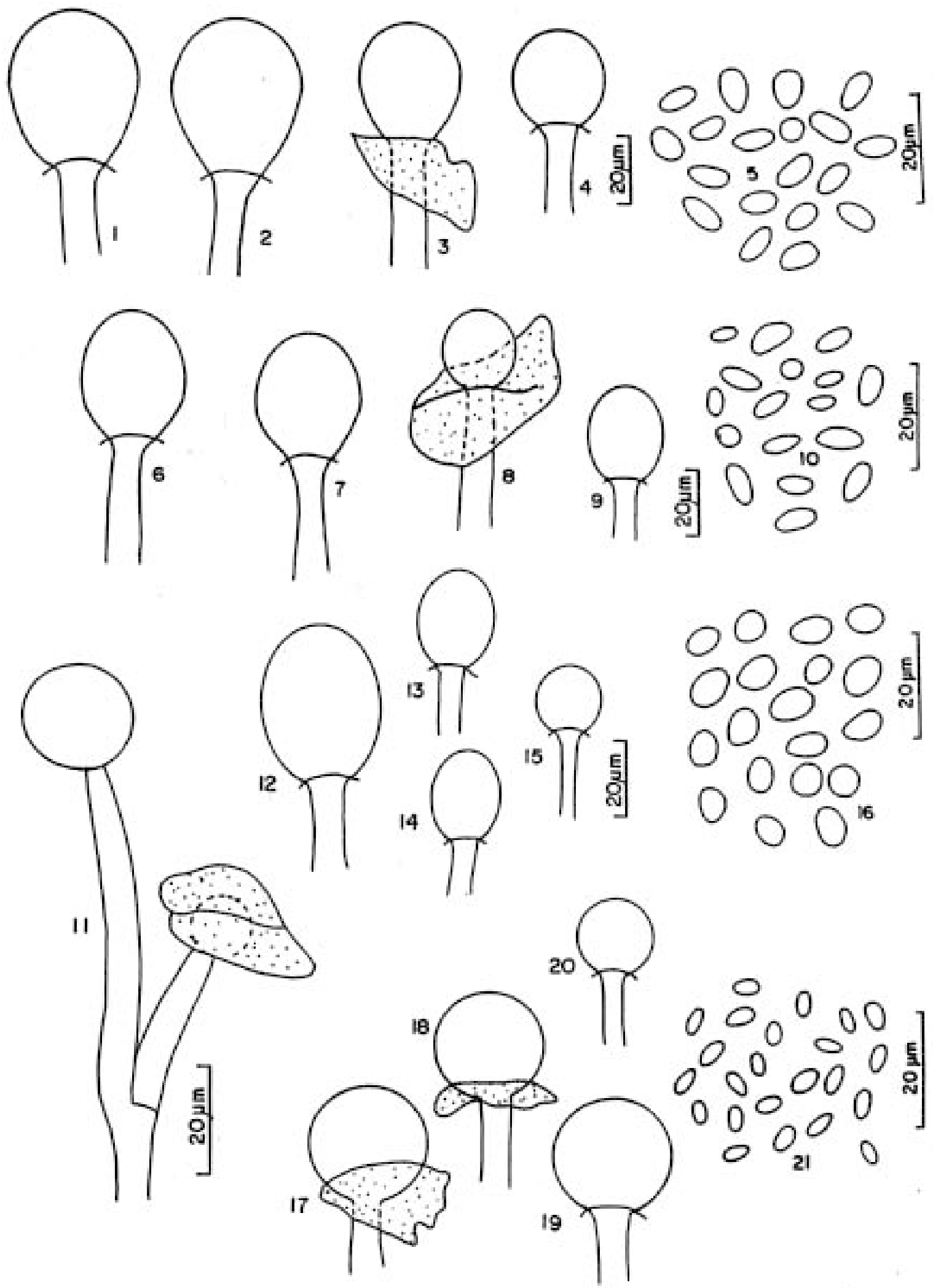

Figuras 1-21. Mucor circinelloides. 1-5. M. circinelloides f. circinelloides. 1-4. Columelas com colarete. 5. Esporangiosporos. 6-10. M. circinelloides f. griseo-cyanus. 6-9. Columelas com colarete. 10. Esporangiosporos. 11-16. M. circinelloides $\mathrm{f}$. janssenii. 11. Aspecto geral mostrando esporângio, columelas e ramificação. 12-15. Columelas com colarete. 16. Esporangiosporos. 17-21. M. circinelloides f. lusitanicus. 17-20. Columelas com colarete. 21. Esporangiosporos. 
isolado de solo e constitui-se na primeira referência para o Estado de Pernambuco.

Mucor hiemalis Wehmer f. hiemalis Annales Mycologici 1:39. 1903.

Figuras 27-30.

Colônia, com cinco dias em SMA, $0,2-1,5 \mathrm{~cm}$ alt. $\times$ $9 \mathrm{~cm}$ diâm., cotonosa densa, verso amarelo-claro, reverso amarelo-abricot. Fototropismo positivo. Esporangióforo 7,5-17,5 $\mu \mathrm{m}$ diâm., ramificado monopodialmente com ou sem conteúdo amarelo, esporângios globosos a levemente depressos 20-90 $\mu \mathrm{m}$, espinulados, parede difluente nos maiores e persistente nos menores, hialinos, amarelos quando jovens a amarelo-escuros com a idade, aspecto brilhante, columelas obovóides 16-70 × 22,5-60 $\mu \mathrm{m}$, às vezes aplanadas, lisas, cinzas, colarete ausente ou vestigial, esporangiosporos de formas variáveis: elipsoidais, ovóides, plano-convexos, 2,5-10 × 2-7,5 $\mu \mathrm{m}$, com conteúdo granuloso, zigosporos não observados.

Isolado de fezes de cavalo (agosto/1997), cabra, coelho e veado-catingueiro (setembro/1997), cotia e veado-catingueiro (dezembro/1997), bisão (maio/1998), col. M.H. Alves. Linhagens registradas: SPC $1.773 \mathrm{e}$ URM 4.193.

$\mathrm{O}$ isolado em pauta apresenta características correspondentes ao descrito por Schipper (1973), que menciona esporangióforo 10-12(14) $\mu \mathrm{m}$ diâm., esporângio até $70 \mu \mathrm{m}$ diâm., columelas elipsoidais $38 \times$ $30 \mu \mathrm{m}$ e esporangiosporos $5,7-8,7 \times 2,7-5,4 \mu \mathrm{m}$, os quais apresentam dimensões menores quando comparados ao material estudado. Por outro lado, a autora ressalta grande variabilidade entre as linhagens estudadas. $M$. hiemalis, em solo, é o mais comum de todas as espécies de Mucor. Este isolado difere de M. genevensis e M. hiemalis f. luteus por apresentar columelas obovóides e esporangiosporos de formas variadas. Este táxon foi referido, para o Estado de São Paulo, por Trufem $(1978,1981 \mathrm{a})$ isolado de amostras de solo, por Schoenlein-Crusius et al. (1996) isolado de amostras de solo afetado por fezes de aves e por Viriato (1996) isolado de amostras de fezes de cavalo, guanaco, cotia, zebra e veado-catingueiro. Cavalcante (2000) isolou representante deste táxon, para o Estado de Pernambuco, de amostras de água e de solo.

Mucor hiemalis Wehmer f. luteus (Linnemann) Schipper, Studies in Mycology 4:33. 1973.

Figuras 31-34.

Colônia, com cinco dias em SMA, 1-1,5 cm alt. $\times$
9 cm diâm., cotonosa densa, amarelo-claro (cor de pele), reverso amarelo-claro a amarelo abricot. Fototropismo positivo. Esporangióforos em uma só camada, $5-15(-7,5) \mu \mathrm{m}$, ramificados monopodialmente, parede com incrustações, esporângios globosos 15-65(-90) $\mu \mathrm{m}$ diâm., hialinos quando jovens a amarelo-escuros com a idade, aspecto brilhante, parede difluente colarete vestigial ou ausente, columelas globosas 12,5-55(-65) $\mu \mathrm{m}$ diâm., esporangiosporos longo-elípticos 2,5-8,1(12,5) × 1-5 $\mu \mathrm{m}$, lisos, variáveis no tamanho, geralmente com um a dois grânulos em cada extremidade, zigosporos não observados.

Isolado em fezes de carneiro (junho/1997), cotia (agosto/setembro/1997), coelho (janeiro/1998), carneiro e cavalo (março/1998), cabra, cotia e carneiro (abril/1998), col. M.H. Alves. Linhagens registradas: SPC 1.774 e URM 4.186.

$\mathrm{O}$ isolado estudado possui caracteres correspondentes ao do material descrito por Schipper (1973) que cita esporângios até 60(70) $\mu \mathrm{m}$ diâm., columelas menores $(45 \times 47) \mu \mathrm{m}$ e esporangiosporos menores $(3,4-9,5 \times 1,4-4) \mu \mathrm{m}$. Este táxon difere de M. hiemalis f. hiemalis por apresentar columelas globosas e esporangiosporos longo-elípticos, e de M. genevensis pela ausência de zigosporos. Trufem (1978, 1981a) fez citação deste táxon para o Estado de São Paulo, isolado de amostras de solo e Schoenlein-Crusius et al. (1996) de solo afetado por fezes de aves. Constitui a primeira referência para o Estado de Pernambuco.

Mucor piriformis Fischer f. piriformis. Phycomycetes. In Rabenhorst's Kryptogamenflora, Die Pilze, IV:191. 1892.

Figuras 35-39.

Colônia, com cinco dias em BDA, até $5 \mathrm{~cm}$ alt. $\times$ $9 \mathrm{~cm}$ diâm., cotonosa frouxa, verso branco com pontos negros referentes aos esporângios sobre o micélio estéril, reverso branco-amarelado. Fototropismo positivo. Esporangióforos (15-)17,5-42,5(-45) $\mu \mathrm{m}$ diâm., dilatação próximo à columela pode ocorrer, isolados ou com ramificações curtas próximas à base, parede com incrustações, esporângios piriformes até $250 \times 112,5 \mu \mathrm{m}$, negros, parede cinza-escura, espinhosa, difluente, columelas variáveis na forma, obovóides, cilíndrico-elipsoidais ou piriformes (42,5-)55-150(-155) $\times(20-) 41,2-100 \mu \mathrm{m}$, cinzas ou castanhas, com conteúdo granular hialinos ou amarelo, colarete vestigial, esporangiosporos elípticos 6,2-13,7(-15) $\times$ $5-11,2(-13,7) \mu \mathrm{m}$, formas globosas e subglobosas, podem 
ocorrer, hialinos, com conteúdo granular amarelo, lisos, zigosporos não observados.

Isolado de fezes de coelho e cavalo (fevereiro/1998), col. M.H. Alves. Linhagens registradas: SPC 1.775 e URM 4.145.

$\mathrm{O}$ isolado possui características semelhantes às mencionadas por Schipper (1975), que cita columelas maiores com até $170 \times 150(190 \times 175) \mu \mathrm{m}$ e esporangiosporos menores (7)-9,5 × 4-(7) $\mu \mathrm{m}$. Também apresenta características semelhantes ao material estudado por Trufem (1981a), que cita esporangióforos 9,5-40 $\mu \mathrm{m}$ diâm., esporângios (96-180) $\mu \mathrm{m}$, columelas (44-100 × 44-88) $\mu \mathrm{m}$ e esporangiosporos (5-12) $\mu \mathrm{m}$, menores. Estas diferenças estão relacionadas com a variabilidade que existe entre as linhagens. $\mathrm{O}$ isolado difere dos demais por apresentar micélio estéril, esporângios, columelas e esporangiosporos de dimensões muito distintas do restante. Foi citado por Trufem (1978, 1981a) para o Estado de São Paulo, isolado de folhedo e solo. Constitui a primeira referência para o Estado de Pernambuco.

Mucor piriformis Fischer f. nanus Alves \& Trufem f. nov. Figuras 40-44.

Coloniae in vitro usque ad $0,2 \mathrm{~cm}$, sporangiophori congesto ramosis simpodialis, sporangia globosis cum paries resistentis, colummelae pyriformis, spore ellipticum, hyalinus.

Colônia, com cinco dias em BDA, até $0,2 \mathrm{~cm}$ alt., esporangióforos densamente ramificados de modo simpodial, esporângios globosos, com parede resistente, columelas piriformes, esporos elípticos, hialinos.

Etimologia: nanus - anão - refere-se à altura da colônia.

Isolado de fezes de bisão (fevereiro/1998), col. M.H. Alves.

Tipo: depositado na Coleção de Culturas de Fungos, Seção de Micologia e Liquenologia do Instituto de Botânica, sob registro SPC 1.776 e Holótipo URM 4.189 .

Este táxon possui características microscópicas de $M$. piriformis Fischer, diferindo por apresentar: colônia mais baixa $(0,2 \mathrm{~cm}$ alt. $\times 9 \mathrm{~cm}$ diâm. $)$, pulverulenta, aspecto de algodão molhado, branca a cinza escura com a idade, ramificações densas, esporangióforos 15-32,5 $\mu \mathrm{m}$ diâm., esporângios globosos $67,5 \times 150 \mu \mathrm{m}$, parede esporangial de aspecto carbonáceo, columelas, acentuadamente piriformes $57,5-125 \times 27,5-100 \mu \mathrm{m}$, esporangiosporos elípticos 7,5-10(-12,5) × 5-7,5(-10) $\mu \mathrm{m}$. Devido às diferenças apresentadas, este isolado está sendo proposto como uma nova forma: $M$. piriformis Fischer f. nanus.

Mucor racemosus Fres. f. chibinensis (Neophytova) Schipper, Studies in Mycology 12:24. 1976.

Figuras 45-50.

Colônia, com cinco dias em SMA, 0,5-1,2 cm alt. $\times 9 \mathrm{~cm}$ diâm., cotonosa frouxa a densa, verso branco-cremoso a cinza-escuro com a idade, reverso branco-acinzentado a amarelo intenso. Fototropismo positivo. Esporangióforos 6,2-12,5 $\mu \mathrm{m}$, diâm., ramificando-se monopodial e simpodialmente com ramificações mais densas próximo ao ápice, parede com incrustações, esporângios globosos a leve depressos 35-65,0(-70) $\mu \mathrm{m}$, hialinos a cinza-escuros com a idade, aspecto brilhante, parede persistente, columelas globosas a leve depressas 11,2-50(-52,5) $\mu \mathrm{m}$, cinzas, colarete presente, esporangiosporos subglobosos a elípticos 3,7-7,5 ×2,5-5 $\mu \mathrm{m}$, hialinos, paredes finamente rugosas, clamidosporos presentes no micélio aéreo variando na forma, cilíndricos 8,7-157,5-17,4 $\mu \mathrm{m}$ ou globosos 17,5 $\mu \mathrm{m}$, abundantes, zigosporos não observados.

Isolado de fezes de cabra (junho/1997), bisão (dezembro/1997), cotia (junho/setembro/novembro/ dezembro/1997, janeiro/março/abril/maio/1998), carneiro (janeiro/1998), coelho (fevereiro/1998), col. M.H. Alves. Linhagens registradas: SPC 1.777 e URM 4.149.

O material isolado possui características semelhantes às descritas por Schipper (1976), que cita colônia mais alta (1-1,5 cm), columelas subglobosas a ovóides $(40 \times 38 \mu \mathrm{m})$ e esporangiosporos maiores (5,5-9,5 $\times 4-7 \mu \mathrm{m})$, diferindo (ligeiramente) do isolado ora em discussão. Por outro lado, a autora ressalta que linhagens estocadas tendem a perder as características originalmente observadas.

O táxon citado difere dos demais por apresentar clamidosporos no micélio aéreo em abundância e de formas variadas. Foi citado por Batista et al. (1961b, c, d, 1964, 1967a) para Recife, isolado de fezes de cavalo, carneiro; foi isolado também de fezes humanas e de solo no Maranhão e Amapá, respectivamente. Upadhyay (1967) menciona a espécie isolada de solos em Pernambuco, Rio Grande do Norte e Alagoas. Santos (2000) e Cavalcante (2000) citaram-na para o Estado de Pernambuco isolada de água e solo, enquanto Viriato (1996) isolou o táxon de solo, no Estado de São Paulo. 

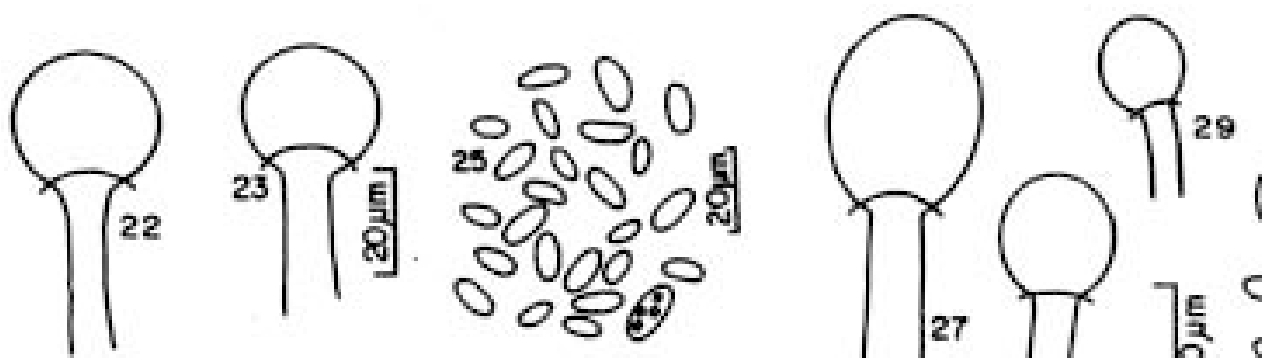

0,00
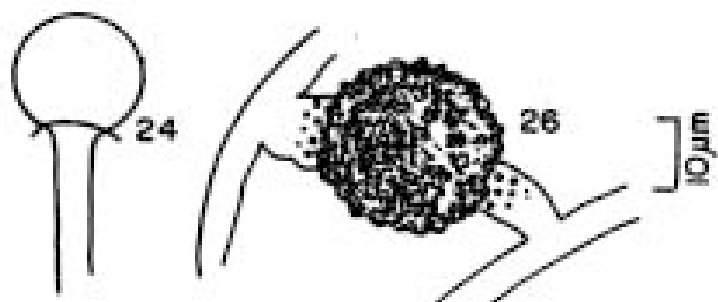

27
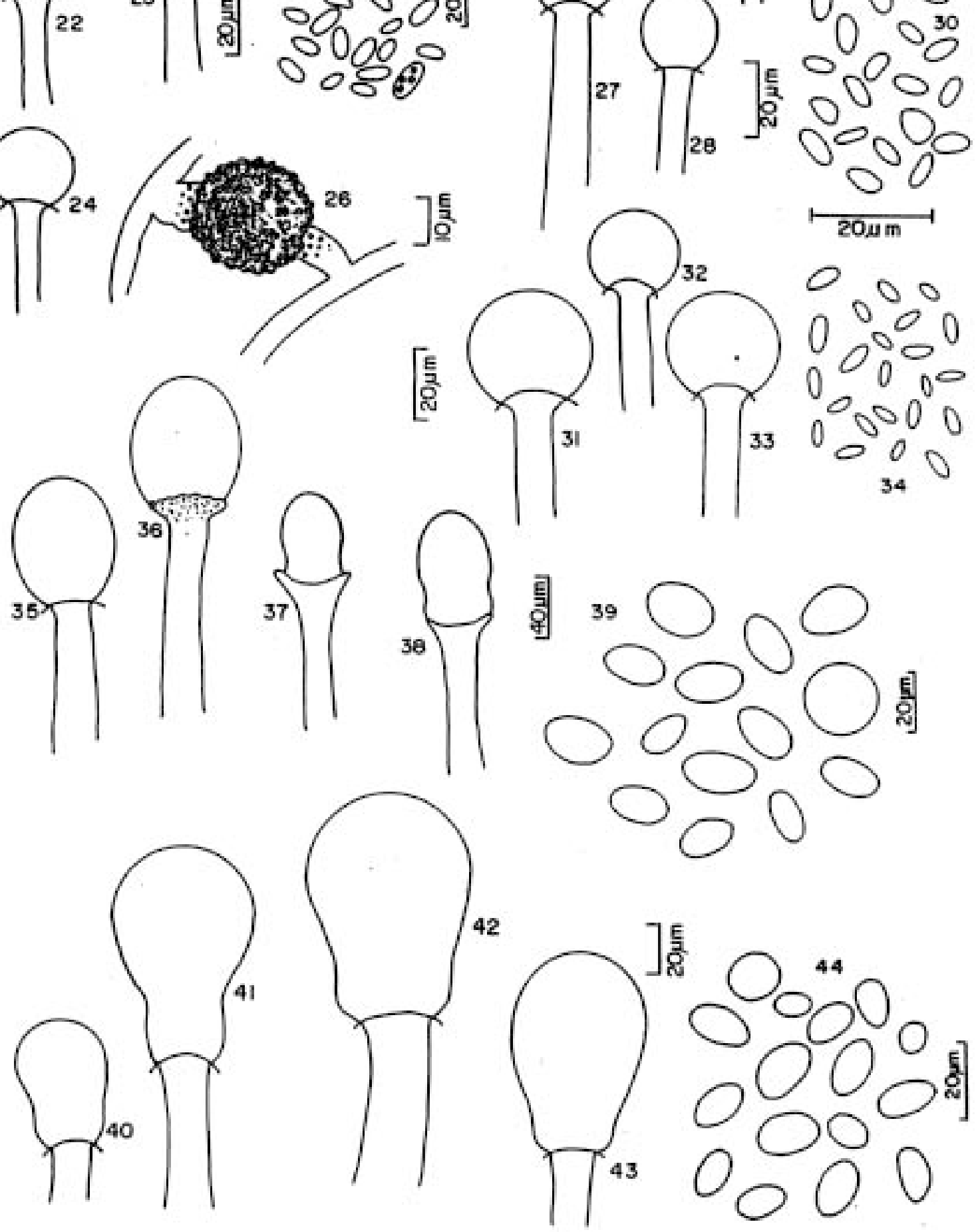

Figuras 22-39. Mucor. 22-26. M. genevensis. 22-24. Columelas. 25. Esporangiosporos. 26. Zigosporos. 27-30. M. hiemalis f. hiemalis. 27-29. Columelas. 30. Esporangiosporos. 31-34. M. hiemalis f. luteus. 31-33. Columelas. 34. Esporangiosporos. 35-39. M. piriformis. 35-38. Columelas. 39. Esporangiosporos. 40-44. M. piriformis f nanus. 40-43. Columelas. 44. Esporangiosporos. 
Mucor subtilissimus Oudem., Ned. Kruidk. Archf 3:463.1898. In Studies in Mycology 17:4. 1978.

Figuras 51-54.

Colônia, com cinco dias em BDA, $1 \mathrm{~cm}$ alt. $\times 8 \mathrm{~cm}$ diâm., cotonosa frouxa, zonada, verso branco com nuances de cinza (devido aos esporângios), aspecto sedoso, reverso branco-amarelado, clareando em direção à periferia. Fototropismo positivo. Esporangióforos 5-12,5 $\mu \mathrm{m}$ diâm., isolados, às vezes com ramificações simpodiais, apresentando constricção abaixo do esporângio, enquanto outros apresentam leve dilatação e cerca de $50 \mu \mathrm{m}$ da columela, parede com incrustações, esporângios globosos a leve depressos 40-65 $\mu \mathrm{m}$ diâm., castanhos, cinza-escuros a negros (sob microscópio estereoscópio), parede difluente, columelas globosas até $45 \mu \mathrm{m}$ no diâm., hialinas, colarete presente, esporangiosporos elípticos 5-8,7(-10) $\times 2,5-$ $3,7(-4,5) \mu \mathrm{m}$, alguns plano-convexos, lisos, geralmente com grânulos nas extremidades, zigosporos não observados.

Isolado de fezes de cavalo (dezembro/1997), col. M.H. Alves. Linhagens registradas: SPC 1.778 e URM 4.133 .

Isolado com características próximas às do material descrito por Schipper (1978). Observou-se, no entanto, que a forma da columela difere ligeiramente da citada por Schipper (globosa a subglobosa, até $33 \mu \mathrm{m}$ e raramente elipsoidal $42 \times 35 \mu \mathrm{m})$. Como estes fungos podem apresentar variações tanto na forma quanto nas dimensões das microestruturas, isto não é significativo. É interessante relatar que este táxon apresenta-se muito delicado: um leve toque e toda a colônia desmorona, diferindo das demais. Viriato (1996) descreve um isolado mencionado como Mucor sp. 2 que apresenta características muito próximas às de $M$. subtilissimus. Esta é a primeira referência de $M$. subtilissimus para o Brasil.

Mucor variosporus Schipper, Studies in Mycology 17:12. 1978.

Figuras 55-59.

Colônia, com cinco dias em BDA, 1,2 cm alt. $\times 9$ $\mathrm{cm}$ diâm., cotonosa frouxa, verso cinza-amarelado, reverso cinza-amarelado-opaco. Fototropismo positivo. Esporangióforos 6,2-11,2 $\mu \mathrm{m}$ diâm., inicialmente isolados, entretanto podem ocorrer ramificações simpodiais, com ramificações longas e curtas, parede com incrustações, com ou sem septos, esporângios globosos a leve depressos 31,2-72,5 $\mu \mathrm{m}$, amarelos, paredes persistentes, columelas globosas 13,7-36,2 $\mu \mathrm{m}$ diâm., às vezes obovóides, cinzas, colares vestigiais, esporangiosporos variáveis na forma, elípticos, cilíndrico-elipsoidais 5-11,2 × 2,5-5 $\mu \mathrm{m}$ ou globosos 5-7,5 $\mu \mathrm{m}$, mas também plano-convexos, hialinos, lisos, grânulos presente, zigosporos não observados.

Isolado de fezes de veado-catingueiro (novembro/ 1997), col. M.H. Alves. Linhagens registradas: SPC 1.779 e URM 4.219.

O material aproxima-se daquele descrito por Schipper (1978) que cita columelas até $72 \times 60 \mu \mathrm{m}$ ou $70 \mu \mathrm{m}$ e esporangiosporos 5,5-13,5 $\times 3,5-5,8 \mu \mathrm{m}$. O presente isolado apresenta as microestruturas menores, o que não é suficiente para sua exclusão pois segundo a autora podem ocorrer variações nas medidas das microestruturas ou nas características morfológicas. $\mathrm{O}$ táxon foi referido, para o Estado de São Paulo, por Schoenlein-Crusius et al. (1996) isolado de solo, constituindo primeira referência para o Brasil.

Os substratos mais favoráveis para o desenvolvimento de táxons de Mucor (tabela 1) foram as fezes de bisão, coelho, cotia e veado-catingueiro que suportaram maior diversidade: cinco ocorrências entre os 12 táxons. Em seguida, tem-se as fezes de cabra, cavalo e carneiro (quatro), eland (duas) e na de boi foi registrado apenas um táxon. Nas fezes de búfalo não foram observados isolados de Mucor. Segundo Dix \& Webster (1995) fezes de diferentes animais e/ou diferentes procedências apresentam micota distinta e animais com rúmen possuem micota mais pobre devido ao fato das enzimas digestivas atuarem mais demoradamente sobre os esporangiosporos. Por outro lado, existe uma flora microbiana mais diversificada atuando de maneira distinta sobre os diversos nutrientes existentes no rúmem. Schoenlein-Crusius et al. (1996), estudando solo afetado por fezes de aves e tendo o solo não afetado como controle, relacionaram 19 táxons de Mucorales. Dentre estes, 10 pertencem ao gênero Mucor, sendo oito de solo afetado e dois de solo não afetado. Entre os táxons encontrados em solo afetado, cinco foram comuns com o presente levantamento (quatro de solo afetado e um de solo não afetado). Estes resultados demonstram maior diversidade de fungos no substrato afetado, provavelmente devido ao maior conteúdo de macro e micronutrientes oriundos das fezes despositadas no solo.

Viriato (1996) estudou 168 amostras de fezes de herbívoros e isolou 32 táxons de Zygomycetes dos quais três foram comuns a fezes e solo. Dentre os 32 táxons, nove pertencem ao gênero Mucor. Desses nove táxons, 


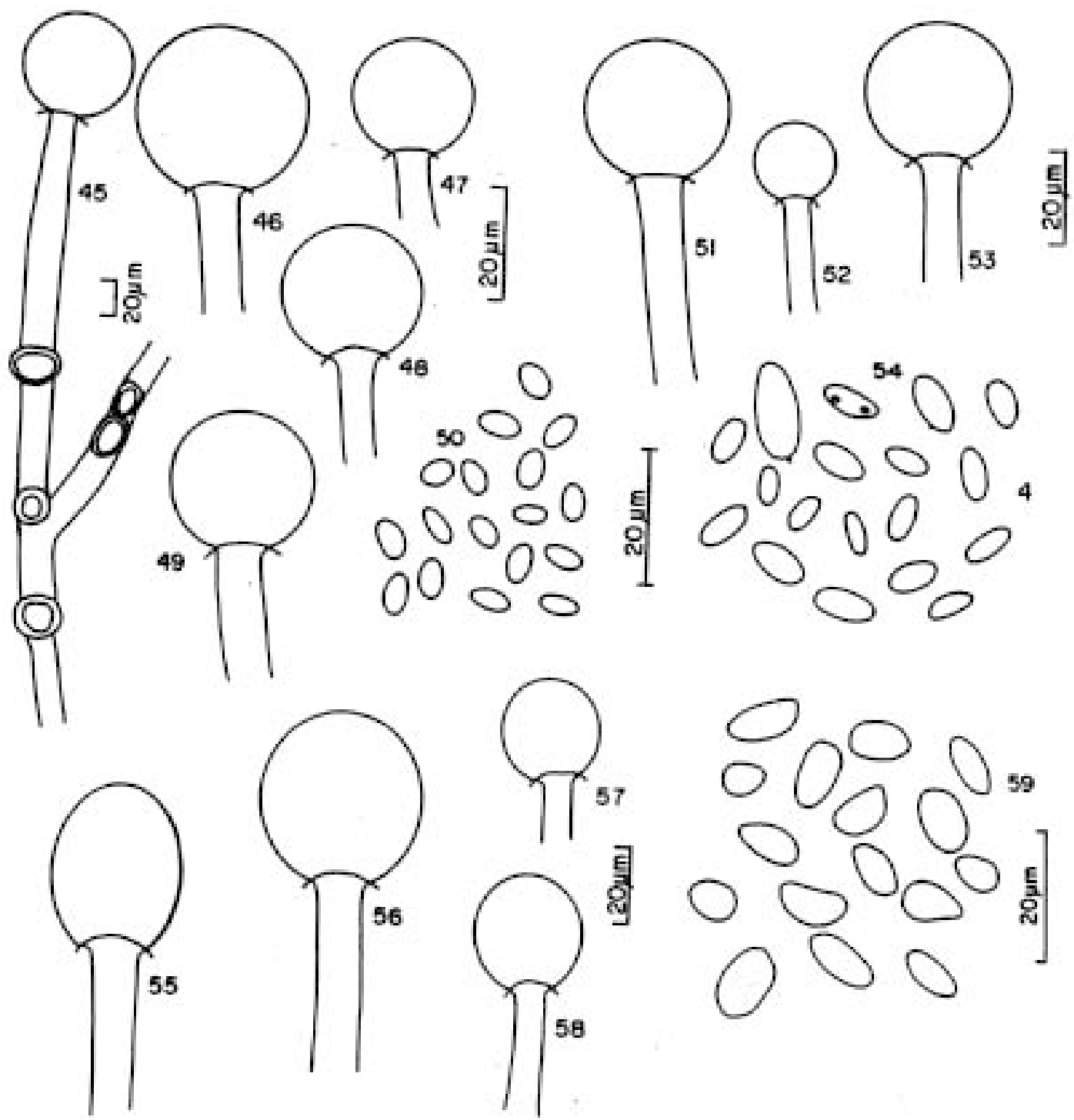

Figuras 45-59. Mucor. 45-50. M. racemosus f. chibinensis. 45. Aspecto geral mostrando ramificação com clamidosporos e columela. 46-49. Columelas. 50. Esporangiosporos. 51-54. M. subtilissimus. 51-53. Columelas. 54. Esporangiosporos. 55-59. M. variosporus. 55-58. Columelas. 59. Esporangiosporos.

44,4\% (M. circinelloides f. janssenii, $M$. racemosus f. racemosus, $M$. mousanensis e $M$. sp2) foram exclusivos de fezes de zebra que não foram estudados no presente trabalho. Por outro lado, os substratos em comum com o encontrado neste estudo foram fezes de cavalo, cotia e veado-catingueiro que apresentaram apenas M. hiemalis f. hiemalis. Estes dados mostram que ocorre seletividade do substrato para o desenvolvimento de táxons de Mucor.

No decorrer do período de coleta, ocorreu pequena oscilação entre o número de táxons isolados que variou de três a quatro por mês, com menor incidência em outubro (duas) (tabela 2). O táxon mais presente durante os meses de coleta foi $M$. racemosus f. chibinensis com nove registros seguido de $M$. circinelloides $\mathrm{f}$. griseo-cyanus e M. hiemalis f. luteus (com seis), M. hiemalis $\mathrm{f}$. hiemalis (com quatro), M. circinelloides f. circinelloides, M. circinelloides f. janssenii e M. genevensis (com três) e os demais táxons com apenas uma ocorrência.

Os mais altos índices de similaridades ocorreram entre as fezes de cotia/carneiro e cabra/coelho (75\% para ambos), seguindo-se cabra/bisão, cabra/cotia e coelho/cotia (66\%) (tabela 3). Bisão, coelho e veado-catingueiro, que favoreceram boa diversidade de táxons (cinco para cada um), não apresentaram necessariamente os maiores índices de similaridade com os demais substratos. Esses dados confirmam os da literatura (Dix \& Webster 1995). 
Tabela 1. Táxons de Mucor assinalados em fezes de herbívoros sob cativeiro no Departamento de Zootecnia da UFRPE e no Parque Dois Irmãos, Recife, Pernambuco, coletados de junho/1997 a maio/1998.

\begin{tabular}{|c|c|c|c|c|c|c|c|c|c|c|c|}
\hline \multirow[t]{2}{*}{ TÁXONS } & \multicolumn{11}{|c|}{ FEZES } \\
\hline & $\begin{array}{l}i \mathbb{8} \\
.00 \\
0\end{array}$ & $\overrightarrow{0}$ & $\begin{array}{l}\text { 䔍 } \\
\text { 苞 }\end{array}$ & $\frac{\pi}{\tilde{U}}$ & $\begin{array}{l}\frac{0}{\pi} \\
\stackrel{\pi}{\pi} \\
\stackrel{\pi}{\pi} \\
\end{array}$ & 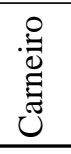 & $\begin{array}{l}\frac{1}{2} \\
\dot{8} \\
\end{array}$ & 苛 & $\begin{array}{l}\vec{\Xi} \\
\frac{\vec{I}}{\Psi I} \\
\end{array}$ & $\begin{array}{l}\frac{8}{\pi} \\
\stackrel{\mathbb{J}}{>} \\
\end{array}$ & 吾 \\
\hline Mucor circinelloides f. circinelloides & + & + & - & - & - & - & - & - & - & - & 02 \\
\hline M. circinelloides f. griseo-cyanus & + & - & - & + & - & + & + & - & + & + & 06 \\
\hline M. circinelloides f. janssenii & - & - & - & - & - & - & + & - & + & + & 03 \\
\hline M. circinelloides $\mathrm{f}$. lusitanicus & - & - & - & - & - & - & - & - & - & + & 01 \\
\hline M. genevensis & - & - & - & - & - & + & - & + & - & - & 02 \\
\hline M. hiemalis f. hiemalis & + & - & - & + & + & - & + & + & - & + & 06 \\
\hline M. hiemalis f. luteus & - & - & - & + & + & + & + & + & - & - & 05 \\
\hline M. piriformis f. piriformis & - & - & - & - & + & - & - & - & - & - & 01 \\
\hline M. piriformis f. nanus & + & - & - & - & - & - & - & - & - & - & 01 \\
\hline M. racemosus f. chibinensis & + & - & - & + & - & - & + & + & - & - & 04 \\
\hline M. subtilissimus & - & - & - & - & + & - & - & - & - & - & 01 \\
\hline M. variosporus & - & - & - & - & - & - & - & - & - & + & 01 \\
\hline Total & 05 & 01 & 00 & 04 & 04 & 03 & 05 & 04 & 02 & 05 & 33 \\
\hline
\end{tabular}

(+) presença da espécie, (-) ausência da espécie

Tabela 2. Táxons de Mucor isolados de fezes de herbívoros vivendo sob cativeiro no Departamento de Zootecnia da UFRPE e no Parque Dois Irmãos, Recife, Pernambuco, coletados de junho/1997 a maio/1998.

\begin{tabular}{|c|c|c|c|c|c|c|c|c|c|c|c|c|c|}
\hline \multirow[t]{2}{*}{ TÁXONS } & \multicolumn{13}{|c|}{ MESES } \\
\hline & Jun. & Jul. & Ago. & Set. & Out. & Nov. & Dez. & Jan. & Fev. & Mar. & Abr. & Maio & Total \\
\hline Mucor circinelloides f. circinelloides & - & + & - & - & - & - & - & + & - & - & - & + & 03 \\
\hline M. circinelloides f. griseo-cyanus & + & - & - & - & + & - & - & - & + & + & + & + & 06 \\
\hline M. circinelloides f. janssenii & - & + & + & - & + & - & - & - & - & - & - & - & 03 \\
\hline M. circinelloides f. lusitanicus & - & - & - & - & - & - & - & - & - & - & + & - & 01 \\
\hline M. genevensis & - & + & - & + & - & + & - & - & - & - & - & - & 03 \\
\hline M. hiemalis f. hiemalis & - & - & + & + & - & - & + & - & - & - & - & + & 04 \\
\hline M. hiemalis f. luteus & + & - & + & + & - & - & - & + & - & + & + & - & 06 \\
\hline M. piriformis & - & - & - & - & - & - & - & - & + & - & - & - & 01 \\
\hline M. piriformis f. nanus & - & - & - & - & - & - & - & - & + & - & - & - & 01 \\
\hline M. racemosus f. chibinensis & + & - & - & + & - & + & + & + & + & + & + & + & 09 \\
\hline M. subtilissimus & - & - & - & - & - & - & + & - & - & - & - & - & 01 \\
\hline M. variosporus & - & - & - & - & - & + & - & - & - & - & - & - & 01 \\
\hline Total & 03 & 03 & 03 & 04 & 02 & 03 & 03 & 03 & 04 & 03 & 04 & 04 & 39 \\
\hline
\end{tabular}

(+) presença da espécie, (-) ausência da espécie 
Tabela 3. Índice de similaridade de Sörensen em relação à ocorrência de táxons de Mucor em função da procedência das fezes de herbívoros.

\begin{tabular}{|c|c|c|c|c|c|c|c|c|c|c|}
\hline $\begin{array}{l}\text { Fezes dos } \\
\text { Herbívoros }\end{array}$ & $\overline{0}$ & $\stackrel{\substack{\mathscr{m} \\
\oplus}}{m}$ & 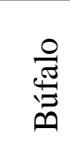 & $\frac{\pi}{\tilde{J}}$ & 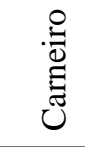 & $\begin{array}{l}\frac{0}{\pi} \\
\stackrel{\pi}{\pi} \\
\tilde{U}\end{array}$ & $\frac{8}{\overline{0}}$ & ن & $\frac{\vec{\Xi}}{\vec{I}}$ & 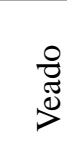 \\
\hline Boi & 100 & 33 & 0 & 0 & 0 & 0 & 0 & 0 & 0 & 0 \\
\hline Bisão & & 100 & 0 & 66 & 25 & 22 & 22 & 40 & 28 & 40 \\
\hline Búfalo & & & 100 & 0 & 0 & 0 & 0 & 0 & 0 & 0 \\
\hline Cabra & & & & 100 & 57 & 50 & 75 & 66 & 33 & 44 \\
\hline Carneiro & & & & & 100 & 57 & 57 & 75 & 0 & 25 \\
\hline Cavalo & & & & & & 100 & 50 & 44 & 0 & 22 \\
\hline Coelho & & & & & & & 100 & 66 & 33 & 44 \\
\hline Cotia & & & & & & & & 100 & 0 & 20 \\
\hline Eland & & & & & & & & & 100 & 57 \\
\hline Veado & & & & & & & & & & 100 \\
\hline
\end{tabular}

Os resultados obtidos demonstram que o substrato utilizado - fezes de herbívoros - é adequado para o desenvolvimneto de representantes do gênero Mucor. Por outro lado, os dados permitiram também, ampliar o conhecimento da biodiversidade e distribuição geográfica destes fungos e forneceram material para coleção de culturas e estudos biotecnológicos.

Agradecimentos - Ao Conselho Nacional de Desenvolvimento Científico e Tecnológico (CNPq) pela bolsa de pós-graduação concedida ao primeiro autor e de produtividade aos demais; ao Departamento de Zootecnia da Universidade Rural de Pernambuco e ao Parque Dois Irmãos da Secretaria do Meio Ambiente do Estado de Pernambuco, pelas facilidades para as coletas, ao Laboratório de Imunopatologia Keizo-Asami - LIKA, da Universidade Federal de Pernambuco e à Seção de Micologia e Liquenologia do Instituto de Botânica (IBt) da Secretaria do Meio Ambiente do Estado de São Paulo, pelas facilidades de acesso aos laboratórios e ao Dr. Jefferson Prado, do Instituto de Botânica, pela diagnose latina.

\section{Referências bibliográficas}

ALEXOPOULOS, C.J., MIMS, C.W. \& BLACKWELL, M. 1996. Introductory mycology. $4^{\text {th }}$ ed. John Wiley $\&$ Sons, New York.

BATISTA, A.C., VASCONCELOS, C.T., FISCHMAN, O. \& STAIB, F. 1961a. Fungos leveduriformes e filamentosos de fezes de bovinos, no Recife. Boletim do Instituto de Micologia da Universidade de Recife 325:1-27.

BATISTA, A.C., VASCONCELOS, C.T., FISCHMAN, O. \& SILVA, J.O. 1961b. Flora micótica intestinal de equinos e asininos, no Recife. Boletim do Instituto de Micologia da Universidade de Recife 326:1-16.
BATISTA, A.C., FISCHMAN, O., VASCONCELOS, C.T. \& ROCHA, I.G. 1961c. Leveduras e outros fungos das fezes de ovinos, caprinos, suinos, galináceos a animais cativos, no Recife. Boletim do Instituto de Micologia da Universidade de Recife 327:1-27.

BATISTA, A.C., VASCONCELOS, C.T., GUEDES, M.D.C. \& CUNHA, P.F.L. 1961d. Fezes humanas: fungos assinalados no Recife. Boletim do Instituto de Micologia da Universidade de Recife 328:1-30.

BATISTA, A.C., BARROS, F.A., SILVA, J.O., CASTRILLON, A.L. \& MACIEL, M.J.P. 1964. Espécies fúngicas do Estado do Maranhão. Boletim do Instituto de Micologia da Universidade de Recife 413:309-318.

BATISTA, A.C., SILVA, J.O., MACIEL, M.J.P., LIMA, J.A. \& MOURA, N.R. 1967a. Micropopulações fúngicas dos solos do Território Federal do Amapá. Boletim do Instituto de Micologia da Universidade de Recife 453:117-130.

BATISTA, A.C., UPADHYAY, H.P., BARROS, N.S.B. \& BEZERRA, J.L. 1967b. Fungos e liquens microscópicos de atividades destrutivas sobre materiais de construção cívil. Boletim do Instituto de Micologia da Universidade de Recife 598:311-342.

BÄRTSCHI, C., BERTHIER, J., GUIGUETTAZ, C. \& VALLA, G.A. 1991. Selective medium for the isolation and enumeration of Mucor species. Mycological Research 95:372-374.

CAVALCANTE, M.S. 2000. Fungos isolados da água e do solo das margens dos Açudes do Prata e do Meio, na Reserva Florestal de Dois Irmãos. Tese de doutorado, Universidade de São Paulo, São Paulo.

DOMSCH, K.H., GAMS, W. \& ANDERSON, T.H. 1995. Compendium of soil fungi. IHW-Verlag, Alemanha.

DIX, N.J. \& WEBSTER, J. 1995. Fungal ecology. Chapman \& Hall, London. 
ESCOBAR, J. \& BARNETT, S.M. 1993. Effect of agitation speed on the synthesis of Mucor miehei acid protease. Enzyme and Microbiol Technology 15:1009-1013.

FOOS, K.M., ROYER, J.A. \& RUCH, D.G. 2001. Simple methods for collecting coprophilous fungi. Micologia Aplicada International 13:51-54.

HESSELTINE, C.W. \& ANDERSON, R.F. 1957. Microbiological production of carotenoides. I. Zygospore and carotene producted by intraspecific and interspecific crones of Choanephoraceae in liquid media. Mycologia 49:449-452.

HESSELTINE, C.W. \& ELLIS, J.J. 1973. Mucorales. In The fungi: an advanced treatise. (G.C. Ainsworth, F.K. Sparrow \& A.S. Sussman, eds.). Academic Press New York, v. 4 B, p. 187-217.

LIRA, N.P. 1971. Espécies de Absidia do solo do Maranhão - Aspectos ecológicos. Boletim do Instituto de Micologia da Universidade de Recife 657:1-6.

O'DONNEL, K.L. 1979. Zygomycetes in culture. University of Georgia, Athens.

PERRAUD, R. \& LABORET, F. 1995. Optimization of metyl propionate production catalised by Mucor miehei lipase. Applied Microbiology and Biotechnology 44:321-326.

PETRUCCIOLI, M. \& FEDERICI, R.G. 1992. A note on the production of extracellular hydrolitic enzymes by yeast-like fungi and related microorgnisms. Annals Microbiology and Enzimology 42:81-86.

RICHARDSON, M.J. 2001. Diversity and occurrence of coprophilous fungi. Mycological Research 105:387-402.

SANTOS, A.C. 2000. Micota filamentosa da água e do solo do Rio Capibaribe, Recife, PE. Tese de doutorado, Universidade de São Paulo, São Paulo.

SCHIPPER, M.A.A. 1973. Study on variability in Mucor hiemalis and related species. Studies in Mycology 4:1-40.

SCHIPPER, M.A.A. 1975. On Mucor mucedo, Mucor flavus and related species. Studies in Mycology 10:1-30.

SCHIPPER, M.A.A. 1976. On Mucor circinelloides, Mucor racemosus and related species. Studies in Mycology 12:1-40.

SCHIPPER, M.A.A. 1978. On certain species of Mucor with a key to all accepted species. Studies in Mycology 17:1-53.

SCHIPPER, M.A.A. 1989. Mucor laxorrhizus. Studies in Mycology 31:151-155.
SCHIPPER, M.A.A. \& SAMSON, R.A. 1994. Miscellaneous notes on Mucoraceae. Mycotaxon 50:475-491.

SCHOENLEIN-CRUSIUS, I.H., TRUFEM, S.F.B., MALATINSKY, S.M.M., NINOMIYA, A. \& ANTUNES, M.F.R. 1996. Mucorales (Zygomycotina) from soil affected by excrement of birds in the "Parque Estadual das Fontes do Ipiranga", São Paulo, Brazil. Revista Brasileira de Botânica 19:7-10.

TRUFEM, S.F.B. 1978. Mucorales (Zygomycetes) do Estado de São Paulo. Dissertação de mestrado, Escola Paulista de Medicina, São Paulo.

TRUFEM, S.F.B. 1981a. Mucorales do Estado de São Paulo 1. Gênero Mucor Micheli. Rickia 9:81-91.

TRUFEM, S.F.B. 1981b. Mucorales do Estado de São Paulo 2. Gêneros Absidia van Tieghem, Gongronella Ribaldi e Rhizopus Ehrenberg. Rickia 9:99-106.

TRUFEM, S.F.B. 1981c. Mucorales do Estado de São Paulo 3. Gêneros Circinella van Tieghem \& Le Monnier e Cunninghamella Matruchot. Rickia 9:113-120.

TRUFEM, S.F.B. 1984. Mucorales do Estado de São Paulo. 4. Espécies coprófilas. Rickia 11:53-64.

TRUFEM, S.F.B. \& VIRIATO, A. 1985. Mucorales do Estado de São Paulo. 6. Mucoraceae coprófilas. Rickia 12:113-123.

UPADHYAY, H.P. 1967. Soil fungi from North-East Brazil. III. Phycomycetes. Mycopathologia et Mycologia Applicata 31:49-62.

UPADHYAY, H.P. 1969. Soil fungi from North-East and North Brazil. VII. Nova Hedwigia 17:65-73.

UPADHYAY, H.P. 1970. Soil fungi from North-East and North Brazil. VIII. Persoonia 6:111-117.

UPADHYAY, H.P. 1973. Helicostylum and Thamnostylum (Mucorales). Mycologia 65:733-751.

VIRIATO, A. \& TRUFEM, S.F.B. 1985a. Mucorales do Estado de São Paulo: 5. Pilobolaceae. Rickia 12:77-88.

VIRIATO, A. \& TRUFEM, S.F.B. 1985b. Mucorales do Estado de São Paulo: 7. Espécies merosporangiadas. Rickia 12:147-154

VIRIATO, A. 1996. Diversidade e aspectos ecológicos de Mucorales (Zygomycetes) de solo e de fezes de herbívoros, no Parque Estadual das Fontes do Ipiranga, São Paulo, SP, Brasil. Dissertação de mestrado, Universidade de Guarulhos, Guarulhos. 